\title{
Advancing the quality of care and nursing practice through emancipatory reflection
}

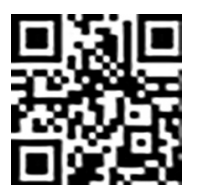

Discussion

Hong-Jing Yua, Dong-Lan Ling ${ }^{b}$, Jia-Le Huc,"

aDepartment of Nursing Administration, The Second Affiliated Hospital of Guangzhou Medical University, Guangzhou, Guangdong 510260, China ${ }^{b}$ Department of Urologic Surgery, The Second Affiliated Hospital of Guangzhou Medical University, Guangzhou, Guangdong 510260, China 'Department of Nurse Anesthesia, Virginia Commonwealth University, Richmond, VA 23284, USA

Received: 21 October 2018; Accepted: 22 December 2018; Published: 20 March 2019

Abstract: Reflection is a fundamental skill of health-care professionals and plays an important role in ensuring the quality of care in health-care practice. It is believed that undertaking reflection in practice can help nurses develop an awareness of a sense of personal power and agency, cultivate their critical thinking ability and help them promote their professional development. However, reflection has not been introduced widely as a nursing curriculum in China, and literature shows that some clinical nurses lack critical thinking skills and critical reflective practice skills by reason of not receiving systematic education on reflection when they were at nursing college. Therefore, we present a series of seven articles focused on prevalent and interesting practice-based events to reflect on in this special issue. The main aim is to disseminate reflective methodology and techniques and present examples of reflective writing for nurses. It is expected that these articles will help to lead Chinese nurses to adopt critical emancipatory reflective processes to bring about transformative actions.

Keywords: Smyth's framework • critical emancipatory reflection • quality of care • nursing practice

(c) Shanxi Medical Periodical Press.

\section{Introduction}

Reflection is a form of enquiry, the purpose of which includes the following: to query take-for-granted assumptions; to look for answers to puzzles or questions that are from real-world observations, dilemmas, and critical incidents; and, eventually, to transform these into action so that professional expertise develops. ${ }^{1}$ It is a fundamental skill of health-care professionals and plays an important role in ensuring the quality of care in health-care practice. Its advantages have been verified in numerous studies, ranging from enabling nurses to raise self-awareness of occurrences of substandard care $^{2}$ and motivating them to continually seek new and better solutions of doing things, ${ }^{3}$ to empowering them to transform professional practice. ${ }^{4}$ As stated by Epp, ${ }^{5}$ solely depending on technical and competence-based practice is not enough to ensure the delivery of holistic and safe patient care, and reflective practice should be highlighted in clinical practice. Moreover, De Vries and Timmins ${ }^{6}$ claim that care erosion (e.g., compassion deficit) could be attributed to failing critical reflection in

How to cite this article: Yu HJ, Ling DL, Hu JL. Advancing the quality of care and nursing practice through emancipatory reflection. Front Nurs. 2019; 1: xx-xx. 
health-care professionals, which eventually leads to the occurrence of tragedies, such as the astonishing scandal of Mid Staffordshire Hospital in the UK. ${ }^{7}$ Thereby, reflection is a significant skill in clinical practice and should be advocated for lifelong learning.

\section{Critical emancipatory reflection}

Four progressive levels of reflection, namely, descriptive reflection, dialogic reflection, critical reflection, and critical emancipatory reflection, are defined by Hatton ${ }^{8}$ and Smyth, ${ }^{9}$ with increased level indicating better reflective processes. Critical emancipatory reflection serves to free the reflectors from their taken-for-granted assumptions and hegemonic threats, which constrain them and their practice. ${ }^{10}$ It allows reflectors to realize that power relationships are subtle and pervasive but underpin all interactions in the workplace, and to understand that these may be preventing effective practice and may not be in patients' best interests. ${ }^{11}$ It also offers reflectors freedom from their own misguided notions and firmly helps in perceptions of themselves and their roles, to provide them with the means to empower themselves and bring about change for the better. ${ }^{11}$ Consequently, it leads to the reflectors developing awareness of a sense of personal power and agency and, thereby, to the challenging and changing of dominant power relations, and finally transforming their action in practice. Therefore, of all types of reflection, critical emancipatory reflection is the richest but riskiest form of reflection considering what it tries to achieve and the courage required to use it effectively. ${ }^{3}$

Considering this, a series of critical emancipatory reflection articles in regard to clinical nursing issues will be published in this magazine. It requires reflectors to make a deep, direct, and systematic analysis of practice issues to figure out the reasons why effective practice is constrained. The task is challenging considering the hegemonic conditions in work settings, but the process of emancipatory reflection has effects and rewards that can be so impressive and profound as to change the habitual ways and go around the reflectors' daily work. ${ }^{10}$

\section{Smyth's framework}

Daily work incidents are imbued with power in practice. If we look closely, we will begin to see subtle and not-sosubtle examples of power plays within health-care settings that are taken for granted as "just the way things are". Using Smyth's framework ${ }^{11}$ for emancipatory reflection and answering a number of questions throughout the four stages (Figure 1) assists in guiding the uninitiated reflector to see self within the context of the particular experience and reflect on it step by step. ${ }^{12}$ It is one of the commonly utilized models in nursing practice, which

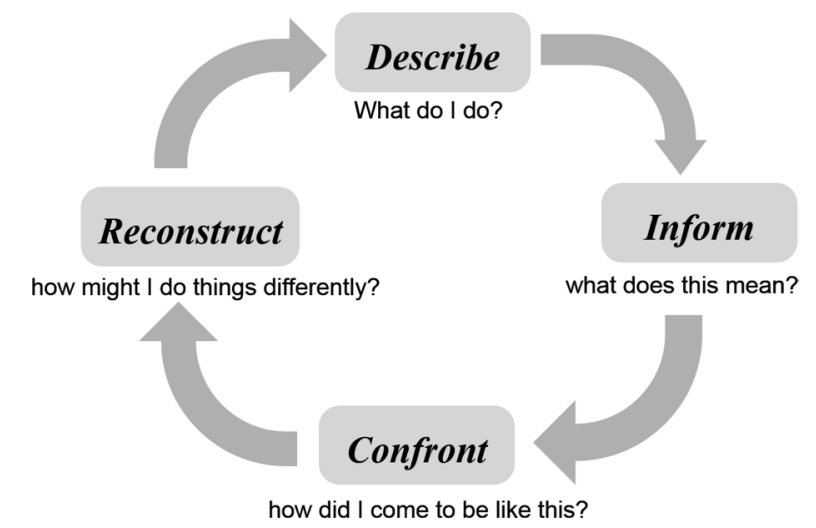

Figure 1. Smyth's ${ }^{11}$ reflective framework.

helps to critique the status quo in the power relationship and increases nurses' awareness of a sense of personal power, autonomy, and agency in their practice and eventually causes positive changes in their work. ${ }^{3}$

Smyth's framework ${ }^{11}$ provides a four-stage process with a key question related to each stage to form a reflective cycle, including describe, inform, confront, and reconstruct. ${ }^{8}$ The first step is "Describe", which allows reflectors to narrate a work scenario experienced previously, recalling all the constraints of the situation. The next step, "Inform", involves unpacking the practice incidents, beginning to think about the assumptions that underpin taken-for-granted actions - "the structured silences" that are presented in nursing - and searching for meaning in the relevant literature. Next, "Confront" involves the following: subjecting the deeply held assumptions and cultural norms about nursing to scrutiny and questioning; uncovering the dynamics of power in relationships; critically questioning implicit economic, historical, political, social, cultural, and personal constraints; and linking the exploration to a review of the empirical evidence. The final step in the process, "Reconstruction", aims to put the scene together again, but now with transformative strategies for bringing changes based on the new understandings and perceptions gained from critical emancipatory reflection. Overall, the application of theoretical perspectives and empirical evidence is vital, especially in the "Inform" and "Confront" stages of Smyth's cycle, because meaningful engagement with the literature will facilitate transformative learning.

\section{Scarcity of reflection education in nursing in China}

It is worth mentioning that reflection is a compulsory curriculum for nursing students to develop their reflective ability in many countries, such as Australia, the UK, and so on..$^{12,13}$ Nonetheless, reflection has not been introduced 
widely as a nursing curriculum in China. ${ }^{14}$ Additionally, student nurses in the UK and Ireland have to maintain a portfolio, which is used to facilitate learning, develop reflective practice skills, and prepare them for professional portfolio work once qualified. ${ }^{15}$ Once they work as a nurse, they are required to reflect on their practice by reflective writing, and these writing works would be kept in their professional portfolios. These portfolios thus can provide evidence of their continuing professional development. In the meantime, their weaknesses and strengths are explored through revisiting, reviewing, and evaluating the reflective writing works to facilitate possible learning. ${ }^{15}$ Nonetheless, the use of a portfolio is not required of a registered nurse in China for such a purpose.

The results of a recent study prove that clinical nurses lack critical thinking skills and critical reflective practice skills because they have not received systematic education on reflection when they were at nursing college. ${ }^{14}$ No literature regarding investigation on Chinese nurses' knowledge and application of reflection could be identified in the database, so the first author conducted a survey among 86 nurses in the author's hospital. Though 35\% of them claim that they know how to write descriptive reflection, $91 \%$ of them state that they do not know how to carry out critical reflective writing and $95 \%$ of them explained that they have never received training with respect to reflective methodology and techniques. As no critical reflective writing articles in the Chinese context could be identified in the literature, we designate a special issue in this magazine and collect seven reflective articles to provide nurses with insightful knowledge of reflection in relation to clinical issues for reference. The main aim is to disseminate reflective methodology and techniques and present examples of reflective writing for nurses. We hope that by reading these papers, readers can enhance their philosophical comprehension of reflection and learn the methodology of reflective writing, as well as inform the growth of the body of knowledge to reflect on clinical issues.

\section{Brief introduction to the seven selected reflection articles}

These seven articles reflect on clinical issues that are of particular interest in China, or in other countries, because these topics are prevalent and puzzle nurses in nursing practice. For instance, in the first article, Ling reflects on a practice-based issue in relation to the working relationship among doctors and nurses. She claims that her work is fully occupied because of the overloaded intravenous transfusion prescribed for each patient, resulting in lack of time for her to engage in dialogue with patients. She fails to recommend doctors to reduce unnecessary transfusion treatment as she lacks self-confidence and feels powerless with regard to decision-making on patients' treatment when confronting doctors. After reflecting on this issue by using Smyth's model, ${ }^{11}$ she is empowered and realizes that, in the future, she should act as a reflective practitioner, creating a daily habit, staying alert to practice, seeing things freshly, finding support systems, improving communication skills, conducting reflective research, and reifying reflective practice. Ultimately, she will be equipped to be able to transform practice and change its outcomes. In the fourth article, the author Xiao reflects on the role of theater nurses in patients' perioperative care. She describes that nurses are frequently being asked questions from patients during their postoperative visits to patients, even though, sometimes, it should be doctors' responsibilities to be there. Occasionally, theater nurses get stuck in these questions because of limitations in their scope of practice, while they could neither refuse to answer patients nor admit their incompetence to answer those questions in order to retain their professional identity in front of patients. Therefore, the author presents such a scenario to reflect on and explore the meanings of the experience. Through the reflective process, she has an insightful understanding of the factors that have influenced her behaviors historically, socially, and culturally and, finally, reconstructs a set of strategies to transform her action.

\section{Conclusions}

We present a series of seven articles focused on prevalent and interesting practice-based events to reflect on in this special issue. We believe that there are many advantages of undertaking nursing reflection in practice, including stimulating learning in practice, developing an awareness of a sense of personal power and agency, cultivating nurses' critical thinking ability, promoting readiness to apply new knowledge, enhancing practice change, helping them promote their professional development, and so on. For these reasons and many others, we believe that emancipatory reflective processes should be adopted when nurses are thwarted by constraints and the power relationship in their practice. By working through the process systematically, nurses may realize that personal constraints are not the only determinants of situational outcomes and that it is possible to construct, confront, deconstruct, and reconstruct their practice. It is expected that these articles will help to lead Chinese nurses to adopt emancipatory reflective processes to bring about transformative action.

\section{Conflicts of interest}

All contributing authors declare no conflicts of interest. 


\section{References}

1. Punch S, Dorrer N, Emond R, McIntosh I. Food Practices in Residential Children's Homes: The Views and Experiences of Staff and Children: A Resource Handbook for Reflection. Stirling: University of Stirling. 2009.

2. Darbyshire P, Ralph N, Caudle H. Nursing's mandate to redefine the sentinel event. J Clin Nurs. 2015;24:1445-1446.

3. Taylor B. Reflective Practice for Healthcare Professionals: A Practical Guide. Berkshire: McGraw-Hill Education. 2010.

4. Farrington $\mathrm{N}$, Townsend $\mathrm{K}$. Enhancing nursepatient communication: a critical reflection. $\mathrm{Br} \mathrm{J}$ Nurs. 2014;23:771-775.

5. Epp S. The value of reflective journaling in undergraduate nursing education: a literature review. Int J Nurs Stud. 2008;45:1379-1388.

6. De Vries J, Timmins F. Care erosion in hospitals: problems in reflective nursing practice and the role of cognitive dissonance. Nurse Educ Today. 2016;38:5-8.

7. Francis R. The mid Staffordshire NHS foundation trust inquiry. 2010. http://tinyurl.com//rh42ch. Accessed 15 August, 2018.
8. Hatton N, Smith D. Reflection in teacher education: towards definition and implementation. Teaching and Teacher Educ. 1995;11:33-49.

9. Smyth J. Developing and sustaining critical reflection in teacher education. J Teacher Educ. 1989;40:2-9.

10. Jasper M. Beginning reflective practice. Nelson Thornes. 2003.

11. Taylor B. Emancipatory reflective practice for overcoming complexities and constraints in holistic health care. Spirituality Health Int. 2003;4:40-45.

12. Nursing and Midwifery Council. Programme specification and curriculum map for diploma. London: Middlesex University. 2009. https://www.mdx. ac.uk/_data/assets/pdf_file/0035/49796/NursingAdult-Dip-Adv-1314.pdf.

13. Ward M. National School Nursing Professional Practice Standards. 2nd ed. 2012.

14. Zhang YF, Zeng TY. Research progress on reflective teaching in nursing education. Chin Nurs Res. 2015;29:1548-1549 (in Chinese).

15. Oermann $\mathrm{MH}$. Developing a professional portfolio in nursing. Orthopaedic Nurs. 2002;21:73-78. 